or of mental alertness with the idle ruminations of prehistoric nightwatchmen by their newly-discovered fires and the favours bestowed on them by females as rewards for their wakefulness.

Stebbins is too good a scientist to draw simple lessons from the faulty and imperfect evidence of human history. As a result, he often reaches conclusions so broad as to be almost lacking in content:

A safe generalization is that genetic templates transmit potentialities and capacities rather than adult behavioural traits . . . . In humans, cultural fitness, based to a large extent on a desire for approval by society, has both a genetic and a cultural basis. Is Homo sapiens just another species of animal that has evolved in the same way as have the various species of monkeys and apes? The answer to this question is a qualified 'no'.

In general, a large part of his answer to the question posed throughout - Can the evolution of man and society be explained in terms of the evolutionary rules affecting lower organisms? - is a similarly resounding "perhaps". The book therefore ends in a curiously flatfooted way: "Is the evolutionist better equipped than anyone else to recommend what is best for human society? Perhaps not"'. This conclusion is an honest one, but betrays the excellence of Stebbins's treatment of the evolutionary process. Darwin to DNA is fine; Molecules to Humanity could be considerably edited with little loss.

J.S. Jones is in the Department of Genetics and Biometry at University College London.

\title{
Naked protoplasm and synchronous nuclei
}

\section{Michael Carlile}

\section{Cell Biology of Physarum and Didymium.}

Vol. 1, Organisms, Nucleus and Cell Cycle. Edited by Henry C. Aldrich and John W. Daniel. Pp.444. ISBN 0-12-049601-1. (Academic: 1982.) \$55, £36.40.

THE myxomycete plasmodium is a remarkable object. A mass of protoplasm not subdivided into cells it can, in the most intensively studied species Physarum polycephalum, attain the size of a dinner plate and contain hundreds of millions of nuclei which divide synchronously, at least twice a day in a well-nourished plasmodium.

A handful of enthusiasts for "naked protoplasm" have studied myxomycete plasmodia for over a century and since 1961, when workers at the McArdle Laboratory for Cancer Research at Madison grew plasmodia of $\boldsymbol{P}$. polycephalum in pure culture on soluble media, many molecular, developmental and cell biologists have carried out work on this organism. A second species, Didymium iridis, has also been the subject of ultrastructural and genetical studies, but here biochemical investigation has been limited through failure to grow plasmodia in pure culture.

In spite of the wide interest in Physarum plasmodia, however, reviewing activity has been limited. Two recent works are now remedying this deficiency. In 1980 Growth and Differentiation in Physarum polycephalum, edited by W. F. Dove and H. P. Rusch, was published by Princeton University Press (for review see Nature 288,$307 ; 1980$ ). Now a different group of authors have contributed to the first of two volumes edited by Henry Aldrich, a leading student of myxomycete ultrastructure, and John Daniel, who with Howard Rusch was responsible for the crucial 1961 paper on pure culture.

The introductory section of the first volume consists of a chapter on the morphology and taxonomy of myxomycetes by Alexopoulos and one on D. iridis by Collins and Betterley, leading authorities on this organism. Subsequent pages are effectively confined to $P$. polycephalum. Tyson deals with periodic phenomena - not only synchronous nuclear division and other periodic events of the nuclear cycle, but also the control of the protoplasmic streaming that occurs in well-defined channels in the plasmodium at rates of up to a millimetre a second with reversals in the direction of flow taking place at approximately one minute intervals. The plasmodium is capable of rapid migration and among the sensory systems guiding migration is chemotaxis, which is being intensively studied in Japan and is reviewed here by Ueda and Kobatake. Protoplasmic streaming and its control is further considered by Kessler.

The difficult subject of Physarum genetics is dealt with ably by Jennifer Dee, the founder of the subject. Two chapters by Mohberg and Babcock then clarify in a succinct way the confusing topics of ploidy and of the genealogy of the strains of $\boldsymbol{P}$. polycephalum in current use. The final four chapters of the first volume deal with nuclear organization (Lafontaine and Cadrin), chromosomal organization (Matthews and Bradbury), DNA (Evans) and RNA (Braun and Seebeck), the important topics of differentiation, metabolism and methodology being deferred to Vol. 2.

This first volume is lucidly written and admirably illustrated. I suspect - and hope - that the two-volume work will do much to promote work on myxomycetes and publicize the results among other biologists.

Michael Carlile is Senior Lecturer in the Department of Pure and Applied Biology, Imperial College, University of London.

\section{Putting the forams in order}

\author{
John W. Murray
}

Foraminifera. By John R. Haynes. Pp.433. ISBN 0-333-28681-2. (Macmillan Press/Halsted: 1982.) $£ 50, \$ 79.95$.

FORAMINIFERA are tiny animals that build themselves a test or shell. Their fossil remains occur in astronomical numbers from the Cambrian to the present day in sediments accumulating in estuaries, seas and oceans. These attributes, together with their great diversity, have made them of use to geologists both for correlating rocks of similar age (biostratigraphy) and for determining the environments of deposition of their enclosing sediment (palaeoecology). In addition, as foraminiferal tests survive the process of drilling boreholes, they are especially useful in the exploration for petroleum.

A sound taxonomic basis is an essential prerequisite for all such studies and $\mathrm{Dr}$ Haynes has taken this as the main theme of his book. In particular, his thorough account of how to write the description of a species and the compilation of a synonymy will prove invaluable to postgraduate students and researchers.

The main thrust of the volume is the introduction of a revised suprageneric classification. As the study of Foraminifera has progressed over the past 200 years, the importance of certain morphological features as criteria for grouping or dividing the species into genera, superfamilies and so on have varied. The revised classification follows previous ones in using the wall structure of the test as the primary means of grouping and subdivision but it takes into account the new information amassed from electron microscopy. Greater importance is attached to details of the aperture than is customarily the case.

Nine orders and thirty-two superfamilies are described. For each order there is discussion of the range of morphology observed, possible evolutionary relationships, an appraisal of their stratigraphic value, comments on their ecology and palaeoecology, and a summary of the classification. The latter includes diagnoses of the superfamilies and of the important genera.

The book is described in the preface as a general text which lays stress on the stratigraphical application of Foraminifera. This aim it achieves admirably with a synthesis of knowledge from more than 1,000 publications, but, in addition, it contains much original work. All those involved in the study of Foraminifera will find it both instructive and stimulating reading.

J. W. Murray is Professor of Geology and Head of the Geology Department at the University of Exeter. 